\title{
A Kind of Coating Method of GaN-MOCVD Graphite Susceptor
}

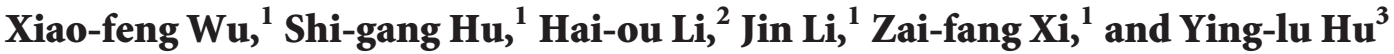 \\ ${ }^{1}$ School of Information and Electrical Engineering, Hunan University of Science and Technology, Xiangtan 411201, China \\ ${ }^{2}$ Guangxi Experiment Center of Information Science, Guilin University of Electronic Technology, Guilin 541004, China \\ ${ }^{3}$ The 41st Institute of China Electronics Technology Group Corporation, Qingdao 266555, China
}

Correspondence should be addressed to Hai-ou Li; seagull_1228@163.com

Received 13 March 2013; Revised 13 May 2013; Accepted 24 May 2013

Academic Editor: Yang Chai

Copyright (C) 2013 Xiao-feng Wu et al. This is an open access article distributed under the Creative Commons Attribution License, which permits unrestricted use, distribution, and reproduction in any medium, provided the original work is properly cited.

\begin{abstract}
A novel coating method for the GaN-MOCVD graphite susceptor is proposed in the paper, which means that the upper surface and sides of the graphite susceptor are covered with a low emissivity material coating, and the surface under the susceptor is covered with a high emissivity $\mathrm{SiC}$ coating. By using finite element analysis software COMSOL Multiphysics, the temperature field of the susceptors without coating, with common SiC coating, and with improved coating is obtained and compared, which shows that the susceptor with the improved coating not only increases the heating efficiency of the heater, but also improves the temperature uniformity of the substrate, which can be of great benefit to the film growth. In addition, this improved coating for the susceptor has the same heating sensitivity as the common $\mathrm{SiC}$ coating.
\end{abstract}

\section{Introduction}

MOCVD (Metal-Organic Chemical Vapor Deposition) technology is a key technology of fabrication of GaN-based optoelectronic and microwave high-power devices, such as blue-light-emitting and high-power laser diodes [1-3]. Presently, the third generation semiconductor industry, with $\mathrm{GaN}$ and nitride compounds as the typical representatives, develops very fast, especially in the semiconductor lighting industry [4-7]. The MOCVD method, which is used to grow the GaN epitaxial film in a large scale, is a key technique. More and more attention has been paid to the research and development of LED epitaxy MOCVD equipment [8-11]. Device performance is mainly determined by the material quality, while the material quality depends on the flow field and the thermal field of the MOCVD reactor.

The MOCVD heating system comprises a heater and a graphite base [12], and the design quality is critical to the temperature field of reactor. Surface treatment and coating of graphite materials have greater impact on thermal characteristics. A lot of researches on them have been done in recent years [13-16]. WU Wen-ming et al. [17] used steadystate calorimeter method and Fourier infrared spectrometer (FTIR) to measure the total hemisphere emissivity at $90^{\circ} \mathrm{C}$ and the normal spectral reflectance at room temperature of $\mathrm{C} / \mathrm{SiC}$ composites, respectively, and they investigated the effect of fiber preform weaving mode, thickness of $\mathrm{SiC}$ coating, and surface morphology on the thermal radiation properties of $\mathrm{C} / \mathrm{SiC}$. Zhu Bo et al. [18] measured the normal spectral emissivity and normal total emissivity of two kinds of carbon fiber by automatic instrument for spectral radiation measurement before and after the graphitization treatment and investigated the effect of graphitization on infrared emissivity property of carbon fibers. Del Re et al. [19] studied the influence of the nitrogen partial pressure, bias voltage, and postannealing on the properties of the AlN/ZrN/AIN low-E coating. The surface of the graphite susceptor in conventional MOCVD reactor is covered with a layer of $\mathrm{SiC}$ coating. The emissivity of $\mathrm{SiC}$ is high [20] and can improve the cooling rate of the graphite susceptor, but the temperature uniformity in the substrate and the heating efficiency will be affected.

An improved coating method of GaN-MOCVD graphite susceptor is presented in this paper. The upper surface and sides of graphite susceptor are covered with a low emissivity material coating, and the bottom surface of the susceptor is covered with an $\mathrm{SiC}$ coating with high emissivity. This method cannot only maintain the heat sensitivity of the graphite susceptor, but also increase the thermal utilization, 


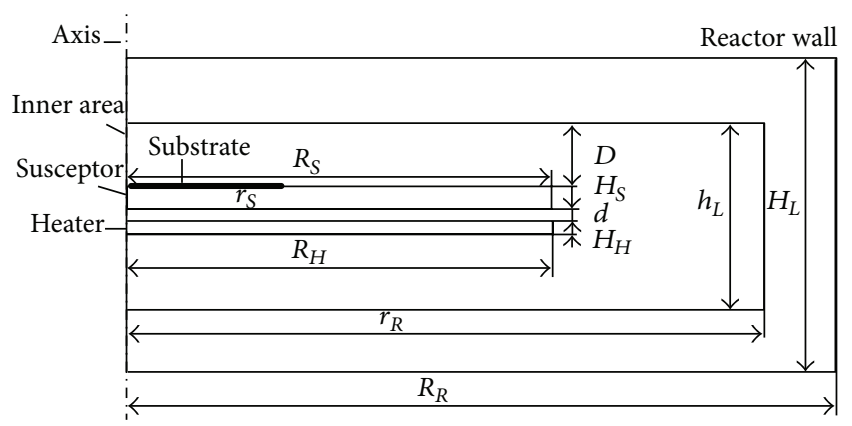

FIGURE 1: 2D axisymmetric model of reactor.

as well as the uniformity of temperature distributions in the substrate.

\section{Simulation Model}

This paper focuses on the temperature distribution of the substrate surface. The following assumptions are made without affecting the main results.

(1) Thermal radiation and thermal conduction are considered in the model, while the heat convection is ignored.

(2) The graphite substrate rotation is not considered.

(3) The gas in the reactor is pure hydrogen under a standard atmosphere pressure.

(4) The outer face of the reactor is set to beatroom temperature.

(5) Only the steady-state distribution is considered in the temperature fields.

(6) The substrate deformation with the different temperatures is not neglected.

Heat conduction equation used in the model is

$$
c \rho \frac{\partial T}{\partial t}=\frac{1}{r} \frac{\partial}{\partial r}\left(k_{i} \frac{\partial T}{\partial r}\right)+\frac{\partial}{\partial z}\left(k_{i} \frac{\partial T}{\partial z}\right) .
$$

The boundary conditions of the susceptor and the reactor inner face are as follows:

$$
-k_{i} \frac{\partial T}{\partial n}=h\left(T-T_{S}\right)+\gamma \sigma\left(T^{4}-T_{S}^{4}\right)+q .
$$

The boundary condition of the reactor outer face is

$$
T=T_{0}
$$

The boundary condition of the axis is

$$
\frac{\partial T}{\partial r}=0
$$

where $c$ is the specific heat, $k_{i}$ is the thermal conductivity of the material $i, \rho$ is the density, $T$ is the temperature, $\gamma$ is the emission rate, $\sigma$ is the Stefan-Boltzmann constant, $h$ is the
TABLE 1: Geometric parameters of reactor model.

\begin{tabular}{lcc}
\hline Description/units & Symbol & Value \\
\hline Reactor outer radius/cm & $R_{R}$ & 11.1 \\
Reactor inner radius/cm & $r_{R}$ & 95.3 \\
Reactor outer height/cm & $H_{L}$ & 12.7 \\
Reactor inner height/cm & $h_{L}$ & 76.2 \\
Graphite susceptor radius/cm & $R_{S}$ & 63.5 \\
Graphite susceptor thickness/cm & $H_{S}$ & 12.7 \\
Heater thickness/cm & $H_{H}$ & 5.08 \\
Heater radius/cm & $R_{H}$ & 15.24 \\
Susceptor upper surface from reactor inner face $/ \mathrm{cm}$ & $D$ & 2.54 \\
Heater top surface from susceptor lower surface/cm & $d$ & 5.08 \\
Substrate thickness/cm & $h_{s}$ & 0.05 \\
Substrate radius/cm & $r_{S}$ & 50.8 \\
\hline
\end{tabular}

heat transfer coefficient, $T_{S}$ is the environmental temperature, $q$ is the absorbed heat, and $T_{0}$ is the room temperature.

The thermal conductivity and the specific heat of the graphite are

$$
\begin{gathered}
k_{\text {graphite }}(T)=37.7 \times e^{-1.96 \times 10^{-4} T} \frac{\mathrm{W}}{\mathrm{m} \cdot \mathrm{K}}, \\
c_{\text {graphite }}(T)=\frac{1}{441.12 T^{-2.3}+7.97 \times 10^{-4} T^{-6.65 \times 10^{-2}}} \frac{\mathrm{J}}{\mathrm{kg} \cdot \mathrm{K}} .
\end{gathered}
$$

The emission rate is

$\gamma_{\text {graphite }}(T)$

$$
= \begin{cases}0.67 & (T \leq 1200 \mathrm{~K}) \\ 3.08 T^{4}-233.7 T^{3}+6.4 & \\ \times 10^{-6} T^{2}-7.4 \times 10^{-3} T+3.75 & (1200 \mathrm{~K}<T \leq 2300 \mathrm{~K}) \\ 0.79 & (T>2300 \mathrm{~K}) .\end{cases}
$$

The density of the graphite is

$$
\rho_{\text {graphite }}=1750 \frac{\mathrm{kg}}{\mathrm{m}^{3}} \text {. }
$$

The $2 \mathrm{D}$ axisymmetric modeling for the MOCVD reactor with infrared heating system is used. It is assumed that internal hydrogen atmosphere is standard state, and the convective heat transfer is neglected. In the paper, the impact of the graphite base is focused on, so a single heater system is used. As shown in Figure 1, the reactor model is made up of simplified 4 portions: the heater, the graphite susceptor, the reactor wall, and the sapphire substrate.

The geometric parameters of the reactor model are shown in Table 1.

Based on the finite element software COMSOL Multiphysics, the thermal conductivity and the thermal radiation law are applicable in the model. The reactor wall is watercooled wall, and the temperature of inner wall is set to be constant at $325 \mathrm{~K}$. 


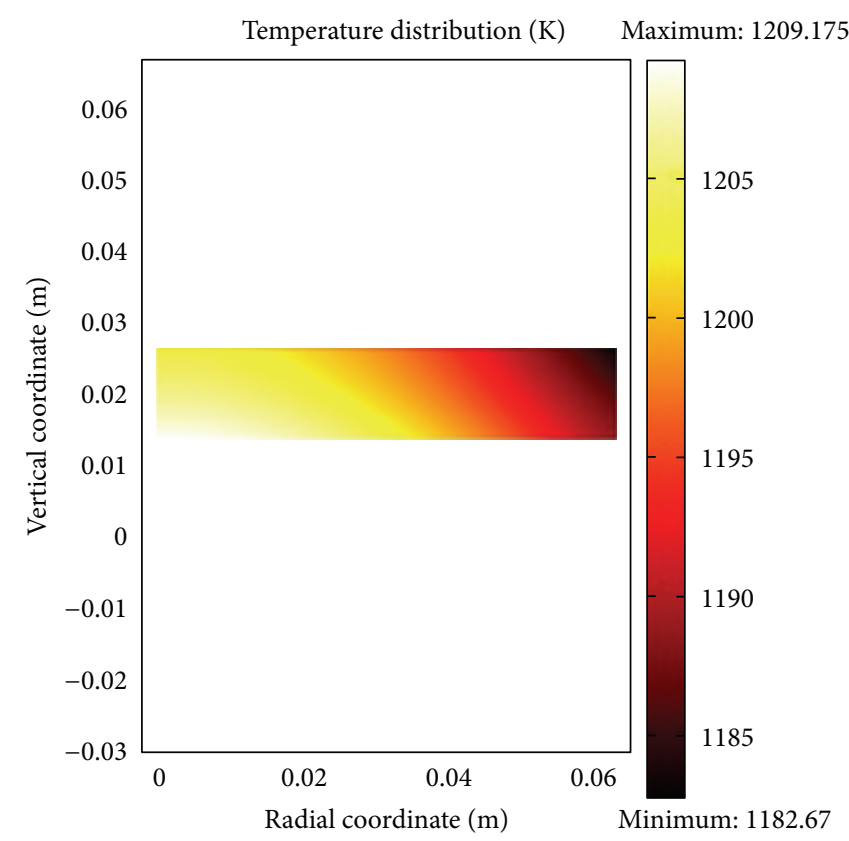

(a)

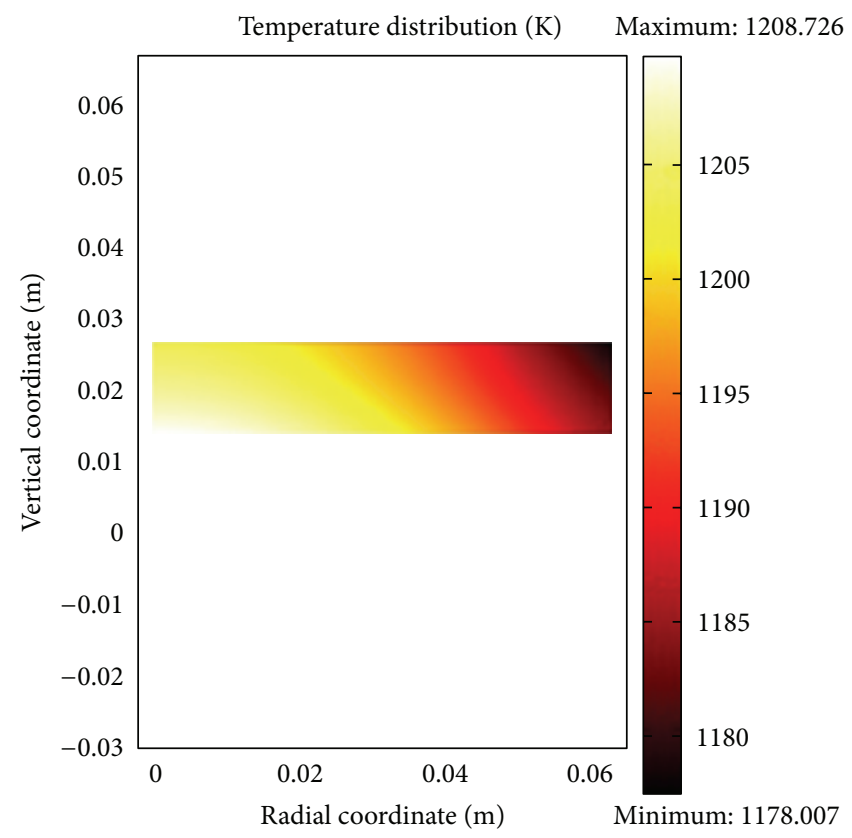

(b)

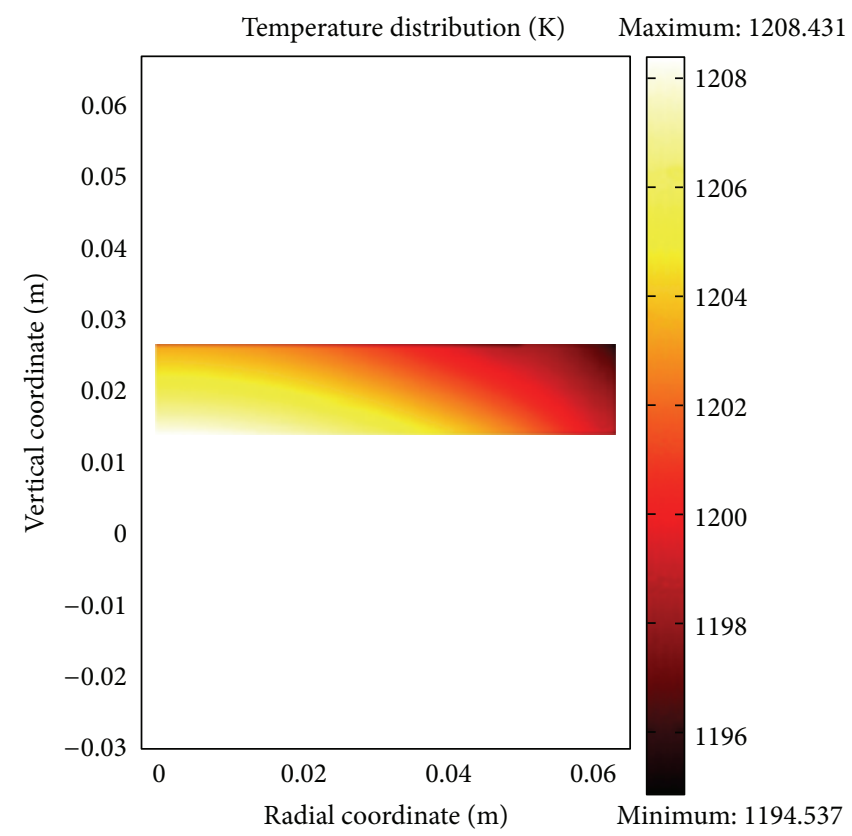

(c)

FIGURE 2: Temperature distribution in susceptors with different coating methods: (a) no coating, (b) common SiC coating, and (c) improved coating.

The surface emissivity of ordinary graphite plate is between 0.5 and 0.79 [21], and in this simulation, it is set to 0.5 . The emissivity of $\mathrm{SiC}$ coating is approximately the same as the emission rate of $\mathrm{SiC}$ [20], which can be represented by Formula 1. Consider

$$
\varepsilon_{\mathrm{SiC}} \approx 0.00011 T+0.768 \quad(700 \mathrm{~K} \leq T \leq 3000 \mathrm{~K}),
$$

where the emission rate of low emissivity material substance is set to 0.1 .

\section{Simulation Results and Analysis}

3.1. Influence of Sapphire Size on the Deformation. The characteristic temperature of $\mathrm{GaN}$ growth is approximately $1195 \mathrm{~K}$. The temperature distributions are calculated in the susceptors without coating, with common SiC coating, and with improved coating, respectively. Figure 2 shows the steady-state distribution of substrate temperature under three coating methods at the temperature of $1195 \mathrm{~K}$. 


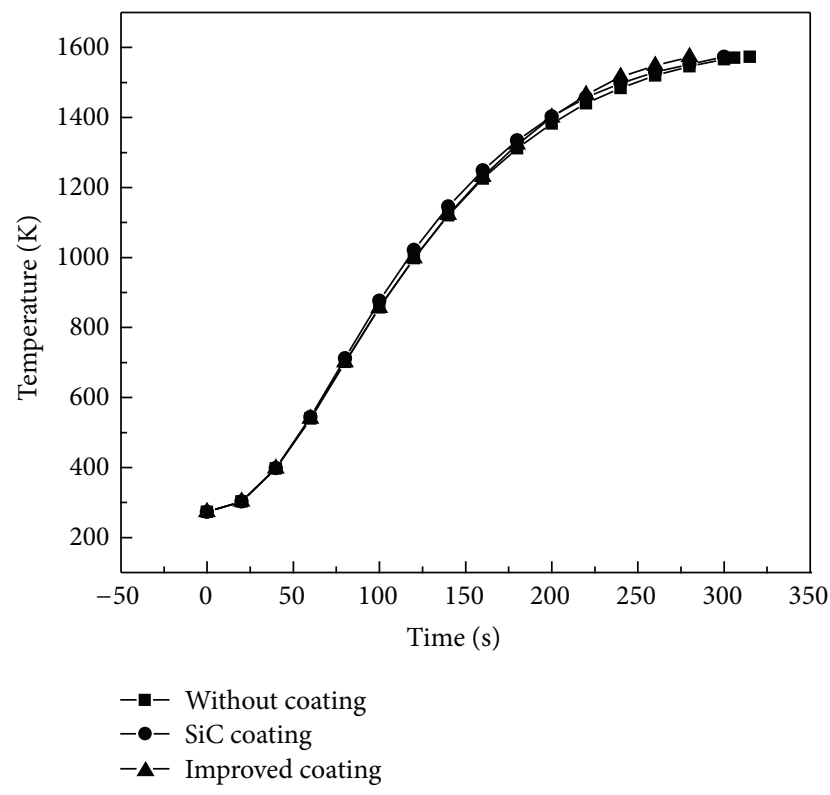

FIGURE 3: Heating processes of graphite susceptors from $273 \mathrm{~K}$ under the condition of triple power heating.

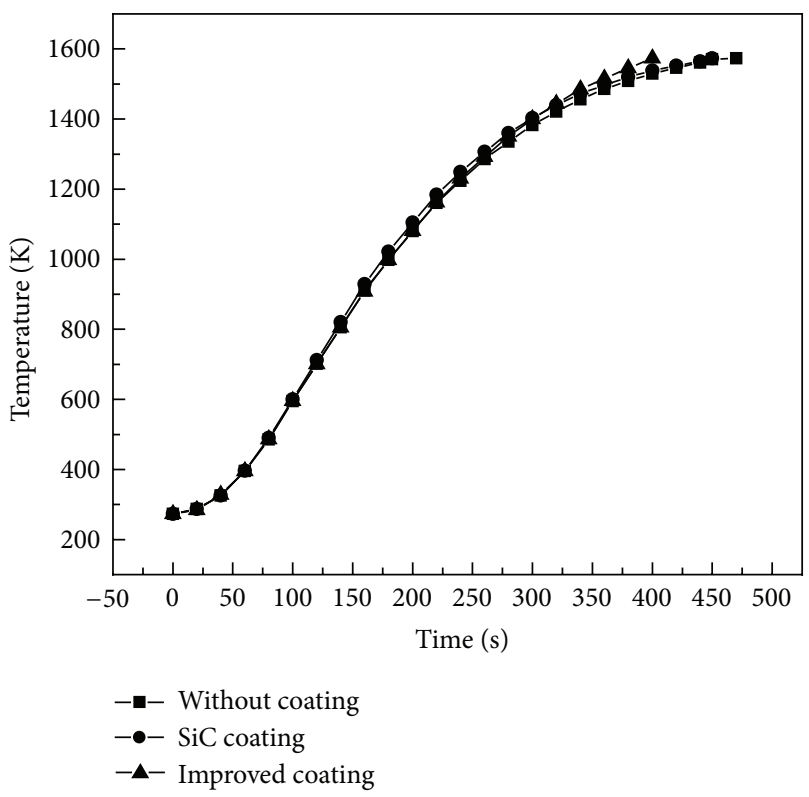

Figure 4: Heating processes of graphite susceptors from $273 \mathrm{~K}$ under the condition of haplotypes power heating.

In order to change the temperature conditions of the epitaxial material growth in time, it is required that the substrate be heated up and cooled down quickly in the MOCVD heating system; thus $\mathrm{SiC}$ is used as the coating of graphite plate generally. For a deep study of effect of the improved coating on the sensitivity, the heating processes of graphite susceptors from $273 \mathrm{~K}$ are simulated under the conditions of haplotypes power $(2381.02 \mathrm{~W})$ heating and triple power $(7143.06 \mathrm{~W})$ heating. Figures 3 and 4 show the heating processes of graphite susceptors from $273 \mathrm{~K}$ under

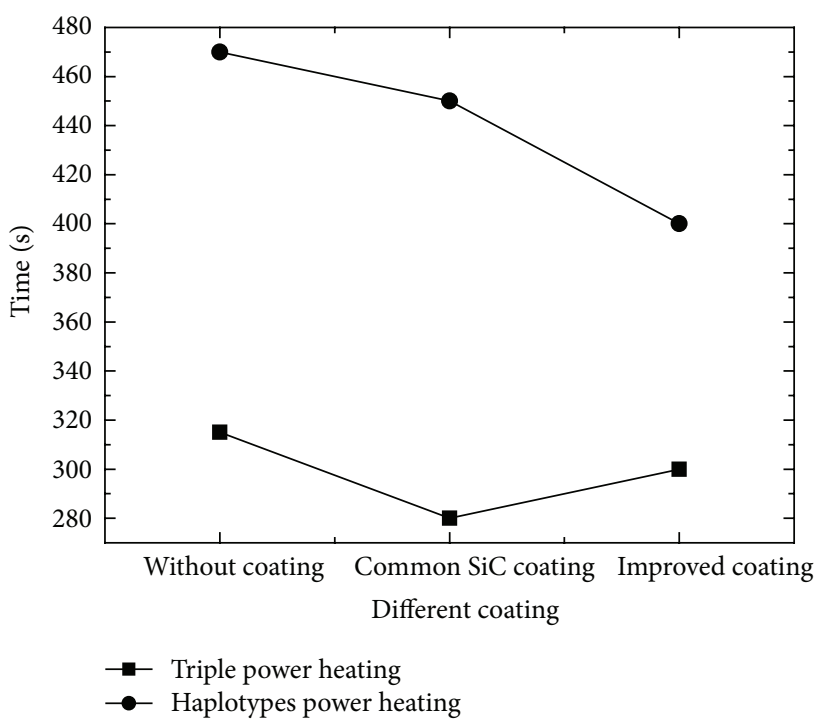

FIGURE 5: Comparison between different coating methods' heating time.

the conditions of triple power heating and haplotypes power heating. The comparison between different coating methods' heating time is shown in Figure 5. By combination of Figures 3,4 , and 5 , it can be seen that temperature rising speed of substrate heating of graphite susceptor with improved coating is comparable to that of graphite susceptor with $\mathrm{SiC}$ coating, even if the single power exceeds the SiC coating, and is faster than that of graphite susceptor without coating. This is mainly because the heating condition of lower surface of the graphite susceptor is comparable to that of $\mathrm{SiC}$ coating, while the emission of the upper surface and the sides is low, so that heat dissipation is slow and a certain insulation effect is played, and the temperature of graphite susceptor rises faster. Therefore, the improved coating has good heat sensitivity. Heating sensitivity using improved coating graphite susceptor is $5 \%-10 \%$ over that using no coating graphite susceptor and is equivalent to using $\mathrm{SiC}$ coating graphite susceptor.

Heat utilization efficiency is the proportion of energy used for heating the substrate surface to all the heat emitted by the heater. Here, the average temperature of the substrate surface can be used to characterize the heat utilization efficiency of the heater. Figure 6 shows the substrate surface temperature distribution of the three kinds of graphite susceptors at the temperature of about $1195 \mathrm{~K}$. The heating power with different heater when heated to $1195 \mathrm{~K}$ is shown in Figure 7. In the three cases of without coating, $\mathrm{SiC}$ coating, and improved coating, the power values of the heater are, respectively, $2233 \mathrm{~W}, 2284 \mathrm{~W}$, and $1866 \mathrm{~W}$. From Figures 2, 6 , and 7 , it can be seen that heat utilization of the heater efficiency is improved with the use of improved coating. It is also due to that the upper surface coating and the sides coating play a thermal insulation effect. Compared with the susceptors without coating and with SiC coating, the heat utilization efficiency of the susceptor with improved coating is increased by $16.4 \%$ and $18.3 \%$, respectively. 


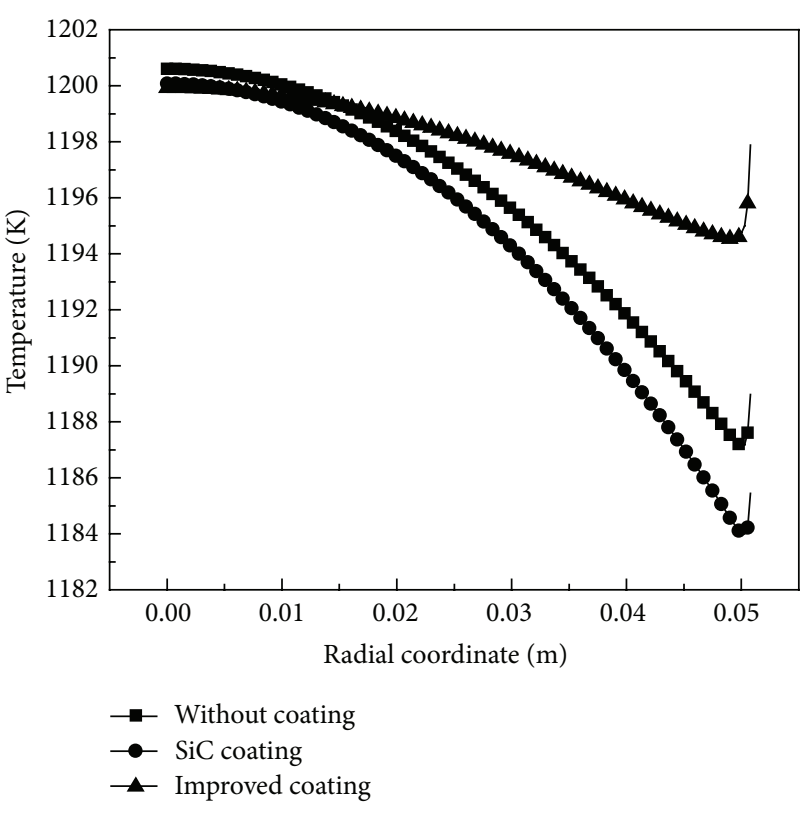

FIGURE 6: Temperature distributions at substrate surface under three conditions.

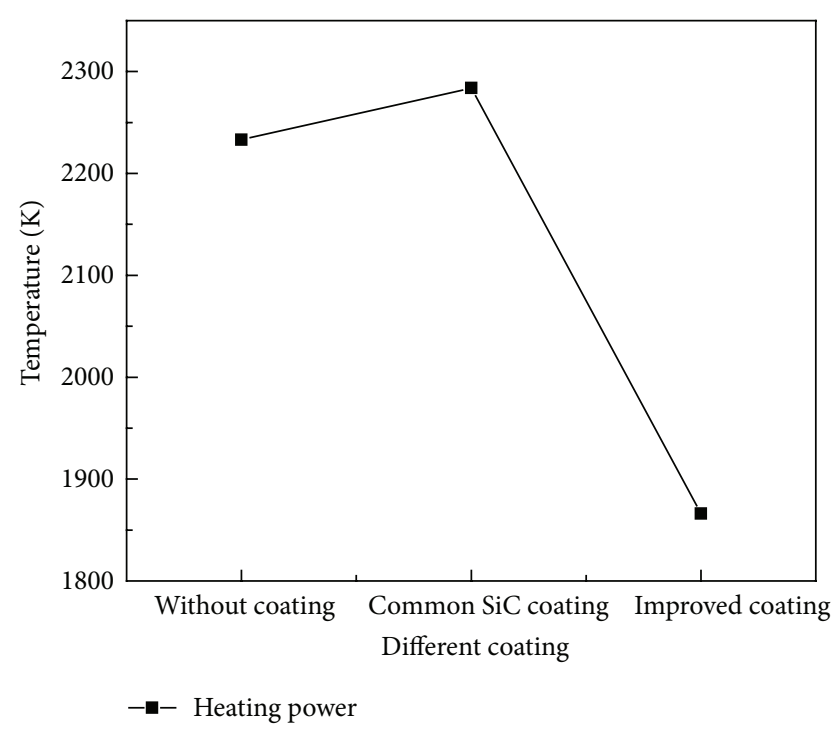

FIGURE 7: Heating power with different heater when heated to $1195 \mathrm{~K}$.

The temperature uniformity of substrate surface has great influence on the consistency of the material growth, which is an important criteria for designing the MOCVD reactor. The effect of improved coating on the temperature uniformity is also studied. The numerical characteristics (namely, the temperature range and the standard deviation) of the temperature distributions in the substrate are shown in Figure 8 under three conditions. As can be seen, as improved coating is used, temperature range is dropped to $5.39 \mathrm{~K}$ from $16.1 \mathrm{~K}$ with/without coating and $13.4 \mathrm{~K}$ with common $\mathrm{SiC}$ coating. The temperature standard is dropped to $1.78 \mathrm{~K}$ from $4.19 \mathrm{~K}$ with/without coating and $4.96 \mathrm{~K}$ with common $\mathrm{SiC}$ coating.

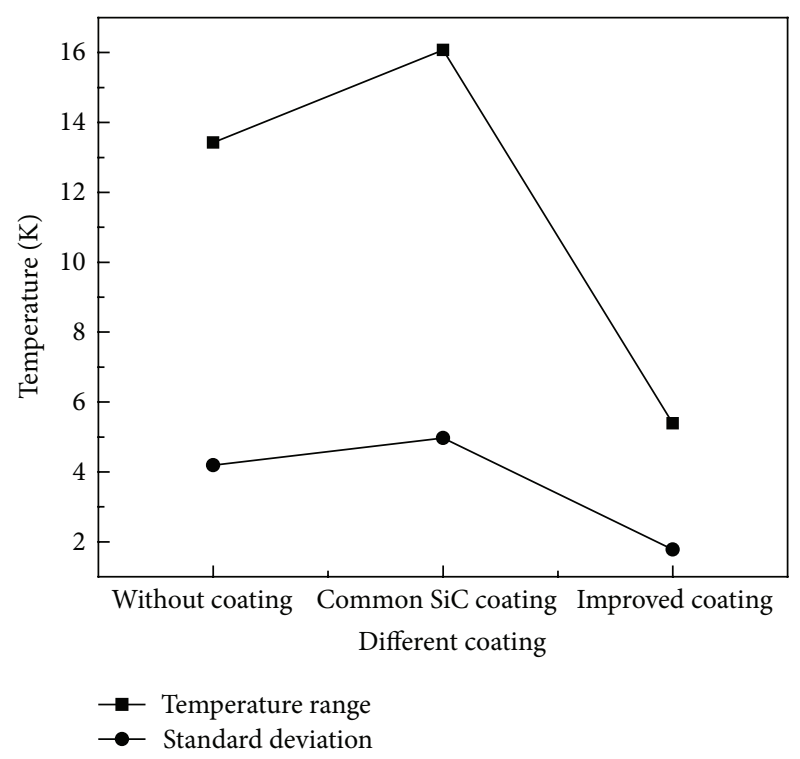

FIGURE 8: Temperature range and temperature standard deviation of substrate surface.

The temperature uniformity in the substrate on the susceptor with improved coating is better than that with common $\mathrm{SiC}$ coating. This is because the temperature is higher in the edge region of the substrate for susceptor with improved coating, which compensates the heat losses brought about by the edge effect of the substrate and improves the temperature uniformity of the substrate surface.

\section{Conclusions}

By using finite element analysis software COMSOL Multiphysics, an improved coating method of GaN-MOCVD graphite susceptor is presented in this paper. Low emissivity material coating is covered on the upper surface and sides of the graphite susceptor, and high emissivity $\mathrm{SiC}$ coating is covered on the lower surface. Using a modified coating, in the case of maintaining the heating sensitivity of graphite susceptor comparable to the susceptor with $\mathrm{SiC}$ coating, the heat utilization efficiency of the heater is improved, so that the temperature uniformity of the substrate surface has been greatly improved.

\section{Acknowledgments}

This project is supported by the National Natural Science Foundation of China (Grant nos. 61274077 and 61274026), the Science and Technology Plan Foundation of Hunan Province (Grant nos. 2012GK3103, 2012GK3102 and 2013FJ2011), the Scientific Research Fund of Hunan Provincial Education Department (12C0108), the Guangxi Department of Education Project (nos. 201202ZD041), and the Guilin City Technology Bureau (20120104-8). 


\section{References}

[1] C. A. Tran, A. Osinski, R. F. Karlicek, and I. Berishev, "Growth of InGaN/GaN multiple-quantum-well blue light-emitting diodes on silicon by metalorganic vapor phase epitaxy," Applied Physics Letters, vol. 75, no. 11, pp. 1494-1496, 1999.

[2] H. O. Li, C. W. Tang, K. J. Chen, and K. M. Lau, "Metamorphic InAlAs/InGaAs HEMTs on GaAs substrates grown by MOCVD," IEEE Electron Device Letters, vol. 29, no. 6, pp. 561564, 2008.

[3] Z. Cheng, S. Hu, W. Zhou, and J. Liu, "Effect of compositedlayer $\mathrm{Al}_{y} \mathrm{Ga}_{1-y} \mathrm{~N}$ on performances of $\mathrm{AlGaN} / \mathrm{GaN}$ HEMT with unintentionally doping barrier $\mathrm{Al}_{x} \mathrm{Ga}_{1-x} \mathrm{~N}$," Microwave and Optical Technology Letters, vol. 53, no. 6, pp. 1206-1209, 2011.

[4] Z. Cheng, S. Hu, J. Liu, and Q. Zhang, "Novel model of a AlGaN/GaN high electron mobility transistor based on an artificial neural network," Chinese Physics B, vol. 20, no. 3, Article ID 036106, 6 pages, 2011.

[5] L. Yang, Z. Chen, J. Zhang, and A. G. Li, “Transport phenomena in a novel large MOCVD reactor for epitaxial growth of $\mathrm{GaN}$ thin films," IEEE Transactions on Semiconductor Manufacturing, vol. 25, no. 1, pp. 16-18, 2012.

[6] H. O. Li, Z. Feng, C. W. Tang, K. J. Chen, and K. M. Lau, "Fabrication of 150-nm T-gate metamorphic AlInAs/GaInAs HEMTs on GaAs substrates by MOCVD," IEEE Electron Device Letters, vol. 29, no. 8, pp. 1224-1226, 2011.

[7] H. Yin, X. Wang, J. Ran et al., "High quality GaN-based LED epitaxial layers grown in a homemade MOCVD system," Journal of Semiconductors, vol. 32, no. 3, Article ID 033002, 4 pages, 2011.

[8] L. Zhao, T. Yu, J. Wu, Z. Yang, and G. Zhang, "Effects of V/III ratio on species diffusion anisotropy in the MOCVD growth of non-polar $\alpha$-plane GaN films," Chinese Physics B, vol. 19, no. 1, Article ID 018101, 4 pages, 2010.

[9] J. Zou, C. Liu, S. Zhou et al., "Growth studies of m-GaN layers on $\mathrm{LiAlO}_{2}$ by MOCVD," Chinese Physics, vol. 15, no. 11, pp. 27062709, 2006.

[10] T. Tao, Z. Zhang, L. Liu et al., "Surface morphology and composition studies in InGaN/GaN film grown by MOCVD," Journal of Semiconductors, vol. 32, no. 8, Article ID 083002, 4 pages, 2011.

[11] Y. Wang, J. Li, S. Li, H. Chen, D. Liu, and J. Kang, "X-ray reflectivity and atomic force microscopy studies of MOCVD grown $\mathrm{Al}_{x} \mathrm{Ga}_{1-x} \mathrm{~N} / \mathrm{GaN}$ superlattice structures," Journal of Semiconductors, vol. 32, no. 4, Article ID 043006, 4 pages, 2011.

[12] Z. Heng and D. Kai, "Design of MOCVD control system on GaN growth," JournaL of Shaanxi University of Technology, vol. 21, no. 3, pp. 28-32, 2005.

[13] K. Chiba, T. Takahashi, T. Kageyama et al., "Low-emissivity coating of amorphous diamond-like carbon/Ag-alloy multilayer on glass," Applied Surface Science, vol. 246, pp. 48-51, 2005.

[14] T. Matsumoto and A. Ono, "Specific heat capacity and emissivity measurements of ribbon-shaped graphite using pulse current heating," International Journal of Thermophysics, vol. 16, no. 1, pp. 267-275, 1995.

[15] L. Peng, S. Yangping, and C. Xinmou, "Progress in research on carbon fibers coated with boron carbide," Material Leader, vol. 22, no. 5, pp. 119-122, 2006.

[16] J. Liu, S. Wang, and W. Huang, "Composition coatings on the surface of carbon steel crucible by aluminizing," Acta Materiae Compositae Sinica, vol. 28, no. 6, pp. 189-193, 2006.
[17] W. Wu, L. Cheng, L. Zhang, Y. Xu, and J. Chen, "Investigation on thermal radiation properties of $\mathrm{C} / \mathrm{SiC}$ composites," Journal of Solid Rocket Technology, vol. 28, no. 4, pp. 303-307, 2005.

[18] B. Zhu, W. Cao, X. Cai, W. Zhao, and C. Wang, "Effect of graphitization on infrared emissivity property of carbon fiber," Material Science and Technology, vol. 19, no. 3, pp. 71-75, 2011.

[19] M. del Re, R. Gouttebaron, J. P. Dauchot, and M. Hecq, "Study of the optical properties of AlN/ZrN/AlN low-e coating," Surface and Coatings Technology, vol. 180-181, pp. 488-495, 2004.

[20] G. Neuer, "Spectral and total emissivity measurements of highly emitting materials," International Journal of Thermophysics, vol. 16, no. 1, pp. 257-265, 1995.

[21] O. Klein and P. Philip, "Transient numerical investigation of induction heating during sublimation growth of silicon carbide single crystals," Journal of Crystal Growth, vol. 247, no. 1-2, pp. 219-235, 2003. 

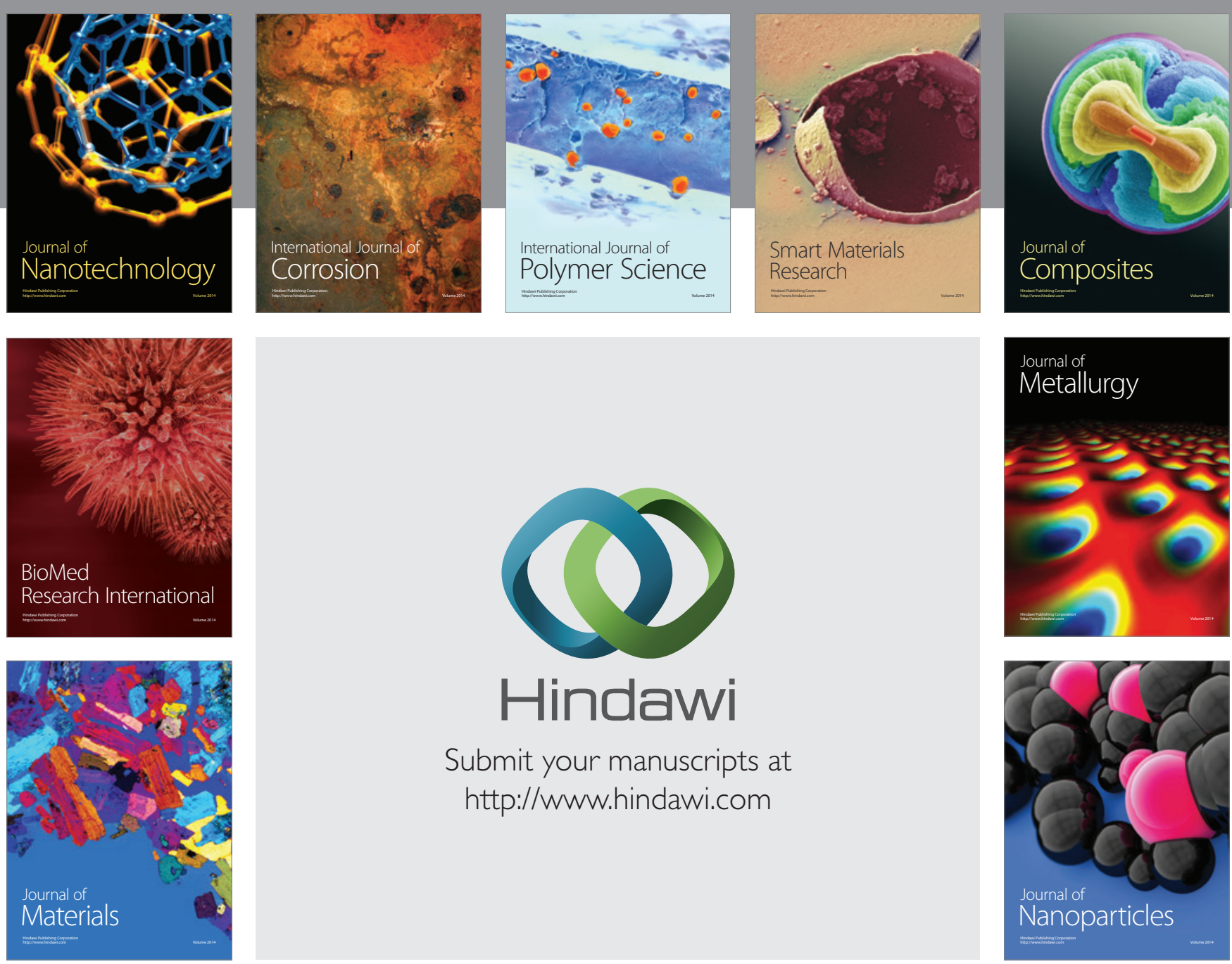

Submit your manuscripts at http://www.hindawi.com
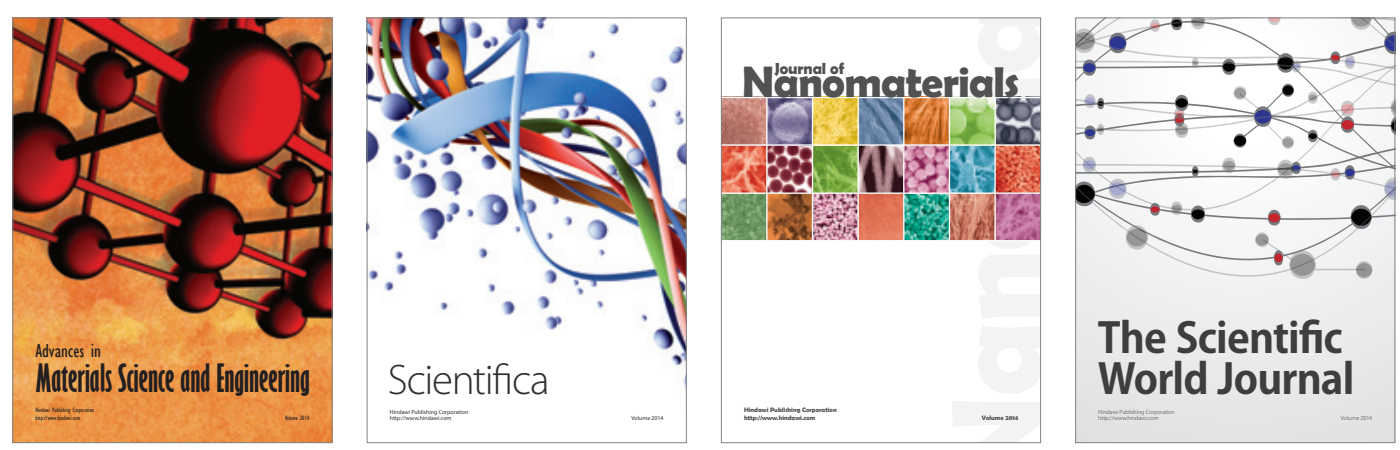

\section{The Scientific World Journal}
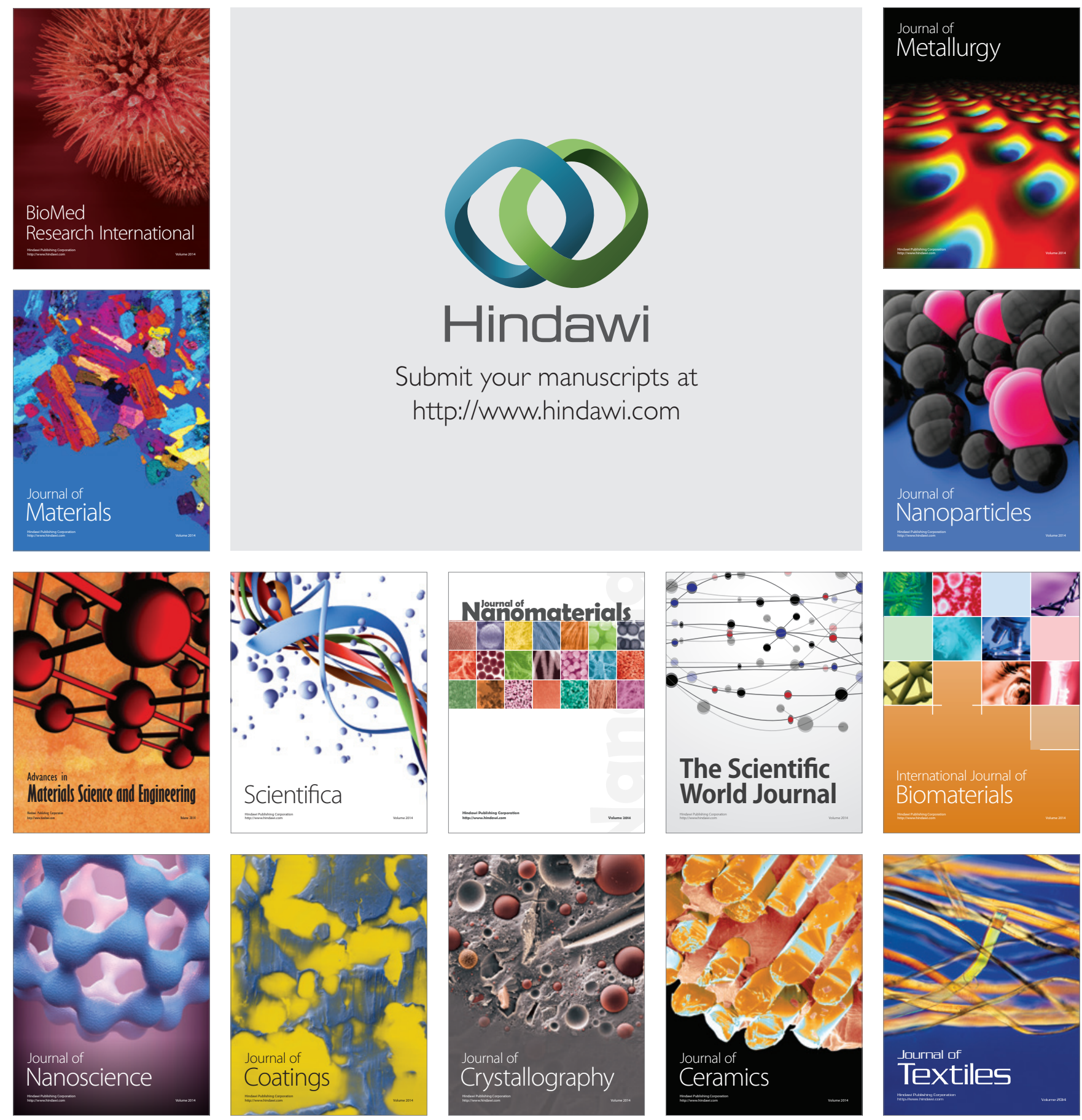